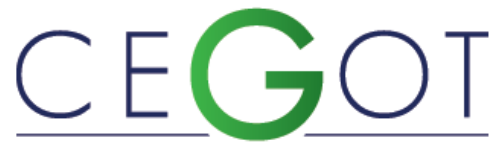

Centro de Estudos de Geografia e Ordenamento do Território
Geografia e Ordenamento do Território, Revista Eletrónica Centro de Estudos de Geografia e Ordenamento do Território http://cegot.org SACCUCCI, ERIKA

Área de Ciencias Sociales y Humanidades- Universidad Católica de Córdoba calle Ituzaingó n 41, piso 2 "B", 5000, Córdoba, Argentina erika sac34@hotmail.com

\title{
La producción de territorios de sacrificio: un análisis de la lucha de VUDAS contra la empresa Porta
}

A produção de territórios de sacrificio: uma análise da luta de VUDAS contra a empresa Porta The production of territorys of sacrifice: an analisis of the strugle of VUDAS against Porta Company

Referência: Saccucci, Erika (2018). La producción de territorios de sacrificio: un análisis de la lucha de VUDAS contra la empresa Porta. Revista de Geografia e Ordenamento do Território (GOT), n. ${ }^{\circ} 15$ (dezembro). Centro de Estudos de Geografia e Ordenamento do Território, p. 363-386, dx.doi.org/10.17127/got/2018.15.015

\section{RESUMEN}

En esta investigación nos hemos centrado en el conflicto de las y los Vecinos Unidos en Defensa de un Ambiente Seguro (VUDAS) en contra de la permanencia de la empresa Porta Hnos productora de bioetanol en Córdoba, a partir del análisis de contenido de once entrevistas en profundidad. Hemos indagado sobre qué territorio se produce a partir de la intersección entre los dispositivos de poder y las estrategias de los sujetos en lucha. Hemos encontrado que el principal dispositivo de poder que opera en este conflicto es aquel de la producción de consenso social. Frente a este dispositivo, las y los vecinos oponen como estrategia la articulación con instituciones en el marco de una lucha por el discurso científico. Hemos arribado a la conclusión que el territorio que se configura se caracteriza por ser un territorio de sacrificio.

Palabras clave: Territorio; Dispositivos de Poder; Estrategias; Medio Ambiente; Conflictos.

\section{ABSTRACT}

In this research we have focused on the conflict of the United neighbors in defense of a safe environment (VUDAS) against the permanence of the company Porta Hnos producer of bioethanol in Córdoba, based on the analysis of the content of eleven interviews in deep. Thus, we have investigated what territory is produced from the intersection between the devices of power and the strategies of the subjects in struggle. We have found that the main device of power that operates in this conflict is the production of social consensus. Faced with this device, neighbors oppose as a strategy the articulation with institutions in the framework of a struggle for scientific discourse. We have arrived at the conclusion that the territory that is configured is characterized by being a territory of sacrifice.

Keywords: Territory; Devices of power; Strategy; Environment; Conflicts. 


\section{RESUMO}

Nesta investigação nos concentramos no conflito dos Vecinos Unidos em Defesa de um Ambiente Seguro (VUDAS) contra a permanência da empresa Porta Hnos produtora de bioetanol em Córdoba, com base na análise de conteúdo de onze entrevistas em profundidade. Investigamos que o território é produzido a partir da interseção entre os dispositivos de poder e as estratégias dos sujeitos em luta. Descobrimos que o principal dispositivo de poder que opera nesse conflito é o da produção do consenso social. Diante desse dispositivo, os vizinhos opõem como estratégia à articulação com instituições no marco de uma luta pelo discurso científico. Chegamos à conclusão de que o território configurado é caracterizado por ser um território de sacrifício

Palavras-chave: Territorio; Dispositivos de poder; Estratégia; Ambiente; Conflito.

\section{Introducción}

América Latina presenta un patrón de acumulación basado en la concentración de la tierra a partir de procesos de exclusión y desposesión, lo cual da lugar a una multiplicidad de conflictos por el territorio. Esta diversidad de conflictos es producto del avance del capital y la consecuente reconfiguración de las disposiciones de uso y valorización del suelo. Esto ha dado lugar a una mayor presión por la tierra como consecuencia de la reprimarización de las economías (Zibechi, 2006) y de lo que algunos autores han llamado como el "consenso de los commodities" (Svampa, 2013). Es en este contexto que se multiplican y profundizan los conflictos por el territorio en América Latina en general y en Argentina en particular.

Así, en la actualidad asistimos a procesos de profundización de las luchas por el territorio, ya sea por su acceso, o bien por sus usos y disposiciones, que en muchos casos atentan contra la vida de la población por sus efectos sobre el medio ambiente. O’ Connor (2000) plantea la insostenibilidad del modelo actual a partir de lo que llama la "segunda contradicción del capitalismo", que refiere a la incompatibilidad que existe entre la feroz avidez de un incremento de ganancias de parte del modelo capitalista y la limitada, y cada vez más reducida, "capacidad de carga" del medio ambiente.

De allí que en este trabajo interesen particularmente aquellos conflictos por el territorio que se organizan en torno a la lucha por las condiciones ambientales y en defensa de la vida. Particularmente nos hemos centrado en el conflicto de las y los Vecinos Unidos en Defensa de un Ambiente Seguro (VUDAS) en contra de la permanencia de la empresa Porta Hnos. 
productora de bioetanol en Córdoba ${ }^{1}$. En este conflicto nos proponemos indagar qué tipo de territorio ${ }^{2}$ se configura a partir de entenderlo como el resultado de un conjunto de dispositivos de poder y de disposiciones sociales que, a partir de la concurrencia de relaciones de fuerza desplegadas en torno al control y la protección de los bienes comunes, configuran sujetos y campos de comportamiento posibles (Ciuffolini, 2011). En otras palabras, hemos propuesto un análisis del conflicto ambiental seleccionado desde un abordaje de las relaciones de poder que se allí se configuran. La efectuación de dichas relaciones de poder- entre los dispositivos y las estrategias- es el territorio.

Los dispositivos de poder organizan la experiencia del presente,regulan laagencia y los límites para la acción en tanto fijan fronteras a los comportamientos posibles. Su operatoria se despliega como un campo de posibilidades que incitan y/o propician determinadas decisiones y acciones, al tiempo que inhiben y/o prohíben otras. Así, los dispositivos se configuran en la unión de elementos heterogéneos: discursos, instituciones, diseños arquitectónicos, decisiones reglamentarias, leyes, medidas administrativas, enunciados científicos, proposiciones filosóficas, morales, entre otras que puedan configurarse y articularse (Foucault, 1994) destinadas a la regulación y control de las acciones de los sujetos y al establecimiento de relaciones sociales reproductivas del orden imperante.

En resumen, un dispositivo se caracteriza por (a) definir una serie de conexiones íntimas entre saber y poder; (b) establecer la dispersión del poder a través una multiplicidad de dispositivos (la vigilancia, el castigo, el examen); (c) describir la producción de modos de subjetivación del individuo a partir de determinadas técnicas (Abadía, 2013); (d) se trata de un conjunto heterogéneo que incluye diversos elementos: discursos, instituciones, edificios, leyes, medidas policíacas, proposiciones filosóficas; (e) siempre tiene una función concreta

\footnotetext{
$1 \mathrm{El}$ análisis aquí presentado forma parte de la tesis doctoral denominada "Los conflictos por la tierra y el ambiente: la (re)producción de los modos de vida" que aborda cinco conflictos por el territorio en Córdoba, en donde se realizaron y analizaron 55 entrevistas en profundidad. Lo que aquí se presenta es el abordaje de uno de esos conflictos.

2 De acuerdo a Giménez, quien retoma los aportes del geógrafo Raffestin, el espacio tiene una relación de anterioridad con respecto al territorio, se caracteríza por su valor de uso. Correlativamente, el territorio es el resultado de la apropiación y valorización del espacio mediante la representación y el trabajo, una "producción" a partir del espacio inscripta en el campo del poder por las relaciones que pone en juego; y en cuanto tal se caracteriza por su "valor de cambio" (Giménez, 1996). A los fines de este trabajo recuperamos estos aportes y los hemos complementado con los conceptos de dispositivos y estrategias a los fines de abordar las relaciones de poder que se ponen en juego en la producción del territorio.
} 
inscrita en una relación de poder; (f) resulta del cruzamiento de relaciones de poder y de saber (Agamben, 2011).

Pero, al mismo tiempo, frente al despliegue de los dispositivos de poder se configuran resistencias y luchas que tensionan su reproducción. En consecuencia, el conflicto es intrínseco al despliegue de los dispositivos en tanto el ejercicio del poder da lugar a la emergencia de resistencias y luchas que los tensionan (Murrillo, 2008). Proponer desde esta perspectiva el abordaje de la configuración de territorios implica reconocer su (re)producción cotidiana al tiempo que recupera la potencia creadora de los sujetos. Permite dar cuenta de las configuraciones del poder pero a su vez señala sus contestaciones en términos de resistencias cotidianas y luchas.

En definitiva, la doble dinámica de hacer posible y de control con que operan los dispositivos, habilita un juego de acciones y decisiones discrecionales. Así pues, los dispositivos son, por un lado, marcos que permiten la creatividad e innovación que requiere la sociedad presente (Guattari, y Rolnik, 2006) y, por el otro, establecen los márgenes de las acciones y decisiones posibles de modo tal que las mismas sean manejables y gobernables (Ciuffolini, 2010).

Se ha propuesto entonces, que el territorio es una efectuación de poder y que, por tanto, puede asumir múltiples formas y características. En su configuración se despliegan y contraponen dispositivos de poder y estrategias que los sujetos producen a los fines de habilitar "espacios de libertad".

Las estrategias son entendidas como las prácticas desarrolladas por los colectivos en el marco de una disputa agonal que se presenta como un juego de posiciones. Se enfrentan y se oponen directamente al despliegue de los dispositivos de poder y al gobierno de los cuerpos, poblaciones y territorios. Estrategia designa los procedimientos utilizados en un enfrentamiento con el fin de privar al adversario de sus medios de combate; se trata, entonces, de los medios destinados a obtener la victoria, la elección de soluciones "ganadoras" (Foucault, 1988). En las estrategias es posible encontrar potencia para la creación de territorios. En este marco, la lucha es el enfrentamiento directo entre diversos sujetos sociales (De Certeau, 1996), un momento del conflicto donde la tensión devino en una contienda o disputa. Se trata de la planificación de acciones de manera metódica en 
virtud de un escenario conflictivo percibido.

En resumen, indagamos en este artículo qué territorio se produce a partir de la intersección entre los dispositivos de poder y las estrategias de los sujetos en lucha. Hemos encontrado que el principal dispositivo de poder que opera en este conflicto es aquel de la producción de consenso social. Frente a este dispositivo, las y los vecinos oponen como estrategia la articulación con instituciones en el marco de una lucha por el discurso científico. Luego del análisis hemos arribado a la conclusión que el territorio que se configura allí en donde intersecta el dispositivo del consenso social y la estrategia de articulación con instituciones, se caracteriza por ser un territorio de sacrificio. La producción de territorios de sacrificio expresan una correlación de fuerzas del dispositivo por encima de la estrategia. Refiere a un tipo de territorio que, aunque en tensión y lucha constante, dificulta y pone en peligro la vida en pos de la acumulación del capital. Se trata de los territorios que "deben ser sacrificados" para el "progreso".

Así, a continuación hemos realizado una presentación del conflicto estudiado y las principales decisiones metodológicas asumidas. En el segundo apartado hemos indagado el funcionamiento del dispositivo de consenso social y posteriormente, en el tercer apartado presentamos la estrategia de articulación con instituciones. Finalmente, hemos propuesto que la característica principal del territorio que se configura es el de sacrificio.

\section{La lucha en contra de Porta hnos.: la producción de Bioetanol}

La empresa Porta hnos. es originariamente productora de alcohol, sin embargo, en el año 2012 incluyó dentro de sus actividades la producción de bioetanol en un marco nacional de promoción de esta actividad ${ }^{3}$. Esta política nacional logró colocar a la Argentina como la

3 En el año 2006 la Argentina sancionó la ley 26093 (Régimen de regulación y promoción para la producción y uso sustentables de Biocombustibles) que establece que a partir de 2010, el gasoil y el diesel oil que se comercialicen en el país, deberán contar en su composición con al menos un $5 \%$ de productos derivados de oleaginosas o cereales. A su vez, prevé beneficios económicos, específicamente exenciones fiscales, para aquellos que se dediquen a la producción de biocombustibles. Las pymes tienen asegurado como consumidores, el $20 \%$ de la producción promocionada otorgada por la Secretaría de Energía. Esta ley fue reglamentada en el 2007 por el Decreto 109 suscripto por el Presidente de la Nación y establece que las actividades alcanzadas por la citada ley comprenden la producción, mezcla, comercialización, distribución, 
séptima productora de bioetanol del mundo, liderado por Estados Unidos y seguido por Brasil (Agrovoz, 23/06/2017). El mapa nacional del bioetanol está integrado por seis provincias: Córdoba, San Luis y Santa Fe, con plantas productoras sobre la base de maíz, mientras que Salta, Tucumán y Jujuy lo hacen a partir de la industrialización de la caña de azúcar. Particularmente Córdoba se ha consolidado como la segunda mayor productora de bioetanol del país: según la Bolsa de Comercio de Rosario (BCR), solo las tres principales empresas de esta provincia tienen una capacidad de producir 372 mil metros cúbicos por año, el 72 por ciento de todo el etanol a base de maíz que se produce en Argentina $\left(514.5000 \mathrm{~m}^{3}\right)$ y el 38,5 por ciento de todo el biocombustible de este tipo que se genera en el país (965.530 $\mathrm{m}^{3}$, de los cuales 450.850 son de caña) (Agrovoz 01-06-2017).

La producción de bioetanol en Córdoba ha ido en aumento. Así, si se tiene en cuenta que para producir un metro cúbico del combustible renovable se requieren 2,5 toneladas de maíz, en el 2017 la demanda del cereal alcanzó a 533 mil toneladas de maíz. Esto representa un aumento de 38.520 toneladas respecto a lo requerido por las tres principales plantas durante los primeros siete meses de 2016, cuando lo demandado fue de 494 mil toneladas (Agrovoz, 28/09/2017).

En este marco general de promoción y desarrollo de la producción de bioetanol, la empresa Porta hnos. adaptó sus instalaciones a los fines de procesar maíz y acceder a los beneficios impositivos.

El conflicto comenzó en 2012 cuando las y los vecinos escucharon sonidos de explosión provenientes de la fábrica. Allí se enteraron que la empresa Porta hnos. había comenzado a producir Bioetanol. Es importante señalar que esta empresa es la única planta productora de bioetanol localizada dentro del ejido urbano, en el corazón de un barrio residencial ${ }^{4}$. Con el pasar del tiempo los olores nauseabundos y la aparición de múltiples afecciones como problemas respiratorios, alergias y problemas en la piel atrajeron la atención de las vecinas que comenzaron a informarse en torno a las consecuencias de este tipo de producción.

consumo y uso de Biocombustibles. La autoridad de aplicación será el Ministerio de Planificación Federal, Inversión Pública y Servicios, a través de la Secretaría de Energía, excepto para los temas fiscales o tributarios. 4 La empresa se encuentra radicada sobre avenida Valparaíso y la colectora de la Circunvalación, en Barrio San Antonio, el cual colinda con los barrios Inaudi, Posta de Vargas, Cañitas, 2 de Abril. Porta Hermanos instaló la planta en el año 1995, unas cuatro décadas después de la formación del barrio Parque San Antonio. Sin embargo, en ese momento la zona era categorizada como industrial. Posteriormente la categorización cambió y desde entonces la planta recibe extensiones gubernamentales en sus permisos de funcionamiento. 
La recurrencia de las enfermedades descriptas y la aparición de casos de cáncer, púrpura y abortos espontáneos las llevó a contactarse con REDUAS (Red Universitaria de Ambiente y Salud) quienes realizaron un primer relevamiento de las afecciones de la zona. La encuesta detectó que 43,2 por ciento de los vecinos tenía cefaleas persistentes y 34,8 por ciento sufría de conjuntivitis y congestión ocular, por encima de la media parámetro (Informe preliminar REDUAS, 2013). De ésta manera, las vecinas organizadas en VUDAS comenzaron a reclamar la relocalización de la planta hacia zonas no habitadas ${ }^{5}$. A continuación se presenta un mapa donde se registran las enfermedades congénitas que se relevaron en 2013. En este mapa se han agregado enfermedades que han sido registradas hasta el 2016:

Mapa de malformaciones congénitas en los barrios San Antonio e Inaudi. Fuente: La Nueva Mañana.

Basados en estos estudios, en 2013 los vecinos realizaron una denuncia penal contra la empresa por contaminación, la cual quedó a cargo del fiscal José Mana que ordenó una pericia científica. Esto resulta de relevancia en tanto era la primera vez que en el fuero penal se realizaba una pericia para medir la contaminación en el aire. La pericia oficial fue realizada por el Centro de Vinculación de Tecnología Química Industrial (Cetequi), de la Facultad de Ciencias Exactas Físicas y Naturales de la Universidad Nacional de Córdoba a cargo del Ingeniero Yorio quien tenía una cátedra de extensión en articulación con la empresa. Finalmente, los resultados fueron inconcluyentes en tanto "no había pruebas suficientes que pudiesen vincular las afecciones con la empresa" por lo cual, la causa fue archivada.

Los primeros años de la lucha se concentraron en acciones directas localizadas en el barrio, al mismo tiempo que se realizaban acciones administrativas en el municipio y la provincia. Sin embargo, al no tener efecto, las vecinas realizaron en 2015 un encadenamiento en el municipio ubicado en el centro de la ciudad. Esta acción es recuperada en la memoria colectiva como un hito que permitió dejar de ser invisibles y el crecimiento del proceso de lucha.

5 La demanda asumió mayor relevancia luego de la explosión de la empresa Raponi, ubicada en Alta Córdoba. Raponi era un depósito de productos químicos ubicado en el barrio Alta Córdoba. Esta empresa sufrió una explosión en 2014 y dejó un saldo de una mujer fallecida, 66 personas heridas (varias de ellas de gravedad) una veintena de viviendas destruidas y otro medio centenar con daños. Esto ponía en evidencia la peligrosidad de una planta productora de alcohol en zonas habitadas. Así, el peligro de la permanencia de Porta no solo se vincula a la producción de bioetanol sino que, además, a la magnitud de la posible explosión. 
A partir del desencadenamiento del conflicto, el discurso científico ha ocupado una centralidad fundamental. Así, la característica principal de este conflicto es la disputa en torno a los resultados de los estudios que han implicado una discusión dentro de VUDAS en torno a las formas de medición y a los vínculos entre el conocimiento y el poder. Así mismo, resulta interesante en tanto aquello que articula la lucha es la "defensa de la vida" en contra de un modo de producción.

En el 2016 las vecinas presentaron un amparo ambiental ante el juez Bustos Fierro, el cual fue rechazado en septiembre de ese año. El amparo era contra la empresa Porta y contra los ministerios de Ambiente y Energía de la Nación. Ante la apelación de los vecinos, la Cámara Federal ordenó reabrir el caso y le derivó el expediente a Vaca Narvaja quien ordenó la primer audiencia de conciliación el día 7 de Agosto de 2017, a la cual solo concurrieron las vecinas. Resulta necesario destacar que se trata del segundo caso de amparo ambiental en todo el país.

Por estas razones, se ha seleccionado este conflicto para su estudio a través de la realización de once entrevistas en profundidad a través de la implementación de la técnica de la bola de nieve. La selección de las entrevistas en profundidad, entre otras posibles, responde a una convicción epistémica y política sobre la importancia de que las investigaciones científicas recuperen la voz de los sujetos en lucha. Se trata de sectores que son escasamente escuchados y sus saberes negados por las instituciones que reclaman saber más que ellos y cuáles son las mejores soluciones para sus necesidades (Ciuffolini, 2015). De esta manera, la producción de conocimiento debe partir del reconocimiento de la voz del otro y de los saberes que allí se expresan.

Para el análisis de los datos se procedió al análisis de contenido de los datos generados durante el trabajo de campo para luego comenzar a indizar algunos elementos discursivos que permitiesen identificar los rasgos característicos que dan cuenta de la especificidad del despliegue del poder sobre este conflicto y las estrategias desarrolladas por el colectivo en lucha. 


\section{El dispositivo de producción de consenso social}

El conflicto por la permanencia de la empresa Porta resulta paradigmático en cuanto a la lucha por la producción de territorios. En escenarios de conflictos por el territorio donde empresas y poblaciones movilizadas pugnan por la definición y control de las formas de producción y reproducción de la vida a nivel local, las empresas desarrollan una serie de dispositivos que, en conjunto, apuntan a configurar sentidos, producir cuerpos y organizar relaciones sociales nuevas y compatibles con el modelo extractivo-exportador, a fin de "neutralizar" los conflictos y garantizar la factibilidad de sus operaciones (Composto, 2012).

En el relato, las entrevistadas señalan con frecuencia las articulaciones que la empresa entabla con diversas instituciones barriales a los fines de mantenerlas bajo su control, a cambio de beneficios económicos. En la siguiente cita se expresan algunas de estas relaciones:

EO1: ¡Si! ¡Si! a la chica esta de Posta de Vargas que tiene la nena, que no es piel de cristal, es una enfermedad parecida, ella vino nos contó que la mamá, Ines Porta le estaba pagando los tratamientos, incluso médicos en el Allende, son unos tratamientos complicadísimos que la nena en vez de mejorar empeoraba, le pagaban las cremas, los remedios, vienen al centro de jubilados y les regalan tortas, bolsones de comida, van al colegio primario, van al colegio secundarios, les ofrecen que les van a hacer el playón. En el primario no se qué les habrán ofrecido pero llevan a los niñitos chiquitos a la planta a visitarla, más o menos... la mecánica que utilizan en las minerías y... de ir comprando, de ir a los centros, a los colegios y ofrecer cosas para que la gente no participe, se calle. De hecho cuando yo he ido a hablar con la directora del colegio de acá no me dio mucha bolilla, me tiró los volantes que yo dejé. EO2: Pero a la empresa si la dejó entrar. EO1: bueno, es que la empresa les ha prometido que les va a techar el playón. EO2: si, bueno pero yo creo que entrar así como así a hablar con los niños. Ellos tienen que tener un permiso $(51: 9)^{6}$

Esta cita refiere a los mecanismos de los que se ha valido la empresa a los fines de construir un marco de alianzas que funcione como respaldo en el conflicto. A través de la articulación con otras instituciones se configura un escenario de control que limita la ampliación del colectivo en lucha. Se produce un escenario de disputa directa en el barrio, donde la construcción del consenso social emerge como dispositivo de poder y las relaciones clientelares e instrumentales como uno de sus mecanismos. Decimos clientelares e instrumentales ya que este tipo de relaciones le permite a la empresa la extensión de su arco de influencias a cambio de favores políticos o, incluso, bienes materiales. El despliegue del dispositivo de producción de consenso habilita la producción de una territorialidad

6 Los códigos que se encuentran al final de los extractos de entrevista son identificatorios. El primer número refiere a la entrevista mientras que el segundo da cuentas del extracto. Ejemplo: (7:1) entrevista 7, cita 1. 
reproductora de las relaciones sociales necesarias para la acumulación. Así entendemos que la producción de consenso es una proceso complejo que requiere de un entramado de construcción cultural, que se realiza mediante una variedad de mecanismos de poder y se lleva adelante por un conjunto de sujetos sociales, tanto del mundo privado como del público (Godfrid, 2015).

En el discurso, se establece una relación entre esta metodología y aquella puesta en práctica por las mineras a cielo abierto. La referencia a una "mecánica" denota la percepción de una articulación de mecanismos que producen dispositivos que disputan el territorio. Así mismo, "ir comprando" refiere a la idea de un avance paulatino, pero estable, sobre estas instituciones que pasan a ser controladas por la empresa a cambio de promesas de bienes materiales.

Desde esta visión, la empresa es percibida como omnipotente en tanto logra "comprar" la mayoría de las voluntades. Un ejemplo de ello es la alusión que se realiza sobre el final del extracto en donde se sugiere una complicidad con el Ministerio de Educación por la habilitación del ingreso de Porta en las escuelas públicas. En este mismo sentido se encuentra la siguiente cita:

\begin{abstract}
Acá en el barrio este Inaudi hay muchos compuestos políticos que es lo que está apoyando a la empresa. ER1: ¿Compuestos políticos? ¿Qué serían? EO1: (risas) y... buscan alianzas, ellos están trabajando y bueno, como te decía, están pagando a gente que es del radicalismo o gente que está en el Centro Vecinal, gente de distintas áreas que estaba trabajando en el barrio por otras cuestiones, bueno como que ellos los han... cooptado eh... con cargos públicos, cargos en la municipalidad o sueldos o cosas entonces ellos trabajan en contra nuestro todo el tiempo. Entonces es muy difícil llegar. Vos pegás los carteles y te los despegan, vos llamás a las reuniones y te ponen cualquier cosa, desinforman a la gente, es como re complicado, es una lucha todos los días. Si nomás cuando fue lo de la municipalidad para que el resto del barrio se enterara fue muy complicado, ellas estaban encadenadas, estábamos un grupo afuera sosteniendo todo el encadenamiento y no recibíamos el apoyo de la gente, la gente no llegaba por que no se enteraba, no salía en ningún medio, no salía en ningún lado y acá se estaba diciendo "Que estas mujeres locas, que están sacadas" y si (51:17).
\end{abstract}

Así, la omnipresencia de Porta se manifiesta incluso como respuesta frente a las estrategias de lucha que el colectivo desarrolla. Emerge en el discurso entonces una clara idea de cercamiento que dificulta la lucha. De allí que la vida cotidiana emerja como el espacio principal de conflicto ya que la disputa y enfrentamiento no es escindible de lo cotidiano. Se trata de una dimensión que resulta transversal a la vida de los sujetos al marcar un antes y 
un después en su modo de vida. Es decir, que todas las dimensiones de la vida pasan a ser espacios de enfrentamiento.

Resulta interesante la emergencia de la expresión "compuestos políticos" que da cuenta de la caracterización que realizan las entrevistadas sobre el propio barrio. Los compuestos políticos se asocian a las vinculaciones que la empresa tiene con funcionarios del gobierno pero también con vecinos comunes que desempeñan un rol en alguna de las instituciones barriales y que fueron "cooptados" por Porta. La idea de "compuestos políticos" refiere entonces a la percepción de poder total que construye la empresa a los fines de desarticular el proceso organizativo. La referencia a "ellos" emerge como "una red", un entrelazamiento del poder al servicio de un modo de producción que excede el caso de esta empresa en particular. Así, Porta despliega un dispositivo que se vale de una serie de mecanismos de desarticulación que asumen sentido a partir del conflicto. Previo al mismo, las vecinas no señalan que la empresa hubiese desarrollado una política hacia el barrio, sino que, esta se desarrolla a partir del enfrentamiento.

La política de la empresa hacia el barrio se basa en un esquema de generación de consenso a partir de un profundo control y disciplinamiento de los sujetos y su agencia. Quienes participan activamente en la lucha encuentran su vida atravesada por esta política, "cuando te quieren joder la vida, te la joden". La vida se encuentra imbuida en un conflicto que encuentra múltiples oponentes, no solo la empresa sino, a su vez, vecinos o incluso familiares.

Las entrevistadas expresan la producción de un sistema de complicidades al cual los sujetos acceden a partir de insertarse en el dispositivo de consenso social. Se construye un imaginario en el discurso que representa a quienes comienzan a formar parte de este sistema como cuerpos en necesidad, que precisan. La satisfacción de estas necesidades produciría sujetos pasivos en cuanto refiere a lo que el propio cuerpo siente y experimenta.

Sin embargo, esta pasividad frente a las "evidencias cotidianas" de contaminación da pasaje a cuerpos activos cuando de truncar la lucha se trata. Así, se construye una idea de estos cuerpos como funcionales a un sistema productivo y a un tipo de territorialidad de sacrificio donde la construcción de un consenso social aparente resulta clave para el poder. Estos cuerpos, a cambio de recursos deben "callarse" y "bajar la cabeza", es decir, renunciar a su 
voz. De esta manera, la empresa se "vale de la necesidad", en otras palabras, le coloca un valor a lo que los cuerpos precisan.

Así, el enfrentamiento se reproduce incluso en el ámbito familiar. Lexemas como "enojo", "bronca" e "indignación" dan cuenta de las tensiones que atraviesan la vida incluso en su dimensión más privada y cotidiana. Las relaciones sociales se encuentran mediadas por si se está "a favor" o en "contra" de la permanencia de Porta. Esto se traduce en la emergencia de nuevas particiones territoriales.

En este sentido, resulta necesario indagar sobre los territorios que se configuran en este conflicto. Hablamos de territorios en tanto el conflicto versa en torno a un enfrentamiento entre dos configuraciones espaciales apropiadas de modos diversos. Por una parte, encontramos el territorio que Porta configura, el cual se encuentra profundamente relacionado con la mercantilización. La mercantilización del territorio refiere a la tierra, las relaciones sociales y los cuerpos.

Así, la mercantilización de la tierra se expresa en la emergencia de una visión particionada del espacio, a través de las referencias a "zonas" o "partes". Es decir, que emerge una idea que trasciende la demarcación espacial del barrio y refiere a una construcción transversal a toda la zona sur de la ciudad. En el discurso de las y los entrevistados la territorialidad que el poder configura se caracteriza por ser "de sacrificio" (Svampa, 2008; Zibechi, 2017). Espacios sacrificables en virtud de posibilitar un modelo de acumulación. Estos territorios de sacrificio asumen sentido en virtud de un sistema en el cual están insertos, un sistema que produce territorios dispensables para garantizar la acumulación.

Por otra parte, la mercantilización de las relaciones sociales se expresa en la configuración de sujetos cuya racionalidad principal es económica. Es decir, implica la reproducción del homus economicus que evalúa sus acciones y las luchas sociales a partir de la lógica de la maximización de beneficios económicos:

EO1: capaz que haciendo un análisis más sociológico se deben colar o entrelazar diversas cuestiones. El barrio nuestro es un barrio clase media ahí, pero es clase media y en algún momento la gente que vino acá tenía idea de que esto fuera EL CERRO DE LAS ROSAS ${ }^{7}$ en un principio y tiene, claro, "No jodan mucho porque se nos va a desvalorizar la propiedad, nadie nos va a comprar la casa" (se

7 Cerro de las Rosas es uno de los barrios de la Ciudad de Córdoba donde residen los sectores de mayor poder adquisitivo. 
superponen dos entrevistadas. EO2: Que si nosotras seguíamos con esto se les iba desvalorizar la casa(52:7)

En esta cita es posible encontrar ambas dimensiones, la mercantilización de la tierra pero también aquella de las relaciones sociales. La primera se expresa a través del cálculo del precio del inmueble y la segunda en la decisión de no participar de la lucha y su impugnación. La misma viene dada por la expectativa de que ésta pueda disminuir el precio de su vivienda. Es decir, se trata de una perspectiva que prioriza el valor de cambio por sobre el valor de uso. Para esta perspectiva, la lucha interfiere con la territorialidad proyectada por algunos vecinos que se encuentra asociada a la idea de "el Cerro de las Rosas", es decir una territorialidad clasista.

Por último, la mercantilización del cuerpo se encuentra presente en las citas anteriores. Alusiones a la "compra" de personas, a "dar" y "recibir algo a cambio" "vender silencio" expresan la idea que los sujetos se encuentran insertos en un mecanismo mercantil. La cita a continuación profundiza esta idea:

\begin{abstract}
Uno de los químicos más contaminantes que uno no pensaría es ese, son los acetaldeídos que los acetaldeídos vienen del vinagre, curiosamente más que del alcohol vienen del vinagre, lo que pasa es que en orgánica, cuando vos producís alcohol, del alcohol también se saca el vinagre. Cuando tenés vinagre y alcohol. Pero ellos producen vinagres, Casalta, alcohol, 1882, los acetos balsámicos, producen el Drop para lavar la ropa, el enjuague y producen todo tipos de licores y aparte el Dogmi sanitario que el alcohol de quemar que es alcohol, altamente cancerígeno, eso se produce acá, como residuos. Acá no se desperdicia una partícula, todo va al mercado, todo es ganancia. Nosotros valemos menos que una partícula de alcohol. [...] Nosotros venimos a ser los conejos de laboratorio, las ratas de laboratorio, en donde te podemos asegurar que las plantas de Bioetanol perjudican la salud del ser humano (54:13).
\end{abstract}

En primera instancia, es importante señalar los adverbios espaciales que aparecen en el discurso de la entrevistada. "Acá" refiere a un espacio difuso, poco delimitado pero que trasciende la empresa y se encuentra profundamente vinculado al mercado. Si "todo" es destinado a la ganancia, incluso sus desperdicios son convertidos en mercancía, aquello que no la produce es la "nada". Sin embargo, emerge un "resto", una "nada" que son los cuerpos de quienes no se "venden". Desde la perspectiva que prioriza la acumulación económica, esos cuerpos no tienen valor, son "el resto", aquello no comercializable. Así, el cuerpo no productivo es desposeído de su condición humana en tanto emerge como "rata" o "conejo" de laboratorio, es decir, como medio para un fin. 
En estas entrevistas el lenguaje de guerra es muy frecuente. Los sujetos se encuentran inmersos en una lucha por la supervivencia frente a un sistema que produce muerte para algunos:

Van saliendo nuevos casos de enfermos y enfermos de cáncer. Esto es muy común, son muertes muy silenciosas y son armas muy silenciosas, no son las armas de la calle donde ves una criminal que te está apuntando con un arma de metal, pero el arma química, es una de las peores digamos, muertes y armas de este siglo, en matar con los químicos, sobre todo si no están siendo controlados. El problema de todo esto es que tampoco, nosotros tenemos el avance tecnológico, y es lo que siempre hablamos, el avance tecnológico lleva un sacrificio, tener un celular en tus manos lleva a un sacrificio en pos de esa tecnología, los pulsos electro magnéticos que tiene, pero si ese avance tecnológico es para matar a muchas personas no tiene sentido el avance, en todo caso no debe estar cerca, en contacto con seres humanos (54:5).

En este discurso, el "avance" conlleva, indefectiblemente, el sacrificio. Sin embargo, se trata del sacrificio de solo algunos para que otros puedan disfrutar del "progreso". El progreso ha producido nuevos modos de muerte más sutiles y silenciosos, pero igual de letales. Así, la referencia a las "armas de este siglo" expresa una lectura estructural y sistémica en donde VUDAS es solo una de sus expresiones. Desde esta perspectiva, la subjetividad se encuentra atravesada por la mercantilización ya que puede comprarse y venderse y, al mismo tiempo, aparece como moneda de cambio, como aquello que debe sacrificarse para la acumulación.

En oposición a esta producción territorial, emerge aquella que se expresa en el discurso de VUDAS. Esta se encuentra anclada a un modo de vida que prioriza el valor de uso frente al valor de cambio. En el discurso de las entrevistadas emerge una idea de un "antes" al cual desearían volver, un momento de la vida anterior a la radicación de la empresa:

Porta ya había estado desde el 95, ya sentíamos olores, estaba al lado de mi casa, yo criando chicos chiquititos con toda la vorágine, llevando los chicos, a la escuela, haciendo la tarea, enseñandolés matemática, lo menos que me preocupaba era que esta empresa cada vez crecía más más más, hasta que un día en el 2012, porque desde el 2012 empezamos a ver muchos movimientos; se talaron los árboles, se taló el bosque que había acá al lado, todo empezó a cambiar, ya no había pájaros, ya no había nada, de pronto el sol entró por todos lados, no había árboles, fue cambiando la fisonomía pero en el término de meses, y empezó a venir camiones trayendo grandes silos que nosotros no sabíamos qué era, eso en el término de unos meses, todo el verano del 2012 empezó a funcionar, a funcionar las calderas, a funcionar (54:22).

En el relato de la entrevista, la instalación de la empresa aparece como un momento de inflexión en la historia personal y en el modo de vida. Los cambios señalados en el extracto expresan el comienzo de la tensión entre la producción de dos territorialidades. Aquella que las vecinas reivindican se basa en el valor de la naturaleza como fin en sí mismo, en la 
posibilidad de "abrir las ventanas" y en la idea de construir un barrio con un sentido de comunidad. Por el contrario, desde la radicación de la empresa, las y los vecinos han optado por "encerrarse" en sus hogares.

De esta manera, es posible encontrar dos producciones de territorios que se encuentran en conflicto. Por una parte, aquella de la empresa Porta y por otra aquella de las y los vecinos. El primer tipo de territorio se caracteriza por el despliegue del dispositivo de consenso social. Así, en este territorio se producen relaciones sociales instrumentales que construyen una red de relaciones y de articulación con diversos sujetos sociales que hacen posible su (re)producción. De esta manera, el dispositivo de consenso social habilita el control del territorio y de las relaciones que allí se configuran. De allí el sentimiento de "omnipotencia" que emerge en el discurso de las entrevistadas. En otras palabras, la mercantilización es la principal característica de este territorio y abarca los cuerpos, las relaciones sociales y el espacio.

Estos mecanismos se despliegan para la producción de territorios de sacrificio,moldeados de acuerdo a las necesidades del capital, donde la vida emerge como dispensable. La mercantilización de la vida se hace evidente donde esta es insertada y sometida al cálculo costo-beneficio en términos económicos. Se configura entonces una vida cotidiana atravesada por el conflicto, donde todos los lazos sociales se encuentran articulados en torno a esta tensión.

En oposición a este territorio, las y los vecinos organizados en VUDAS luchan por la producción de un territorio para la vida que se caracteriza por la afirmación y valoración de los cuerpos que allí habitan así como también, la lucha por la preservación de la vida. De allí que el lenguaje de guerra sea recurrente en este conflicto ya que aquello que se encuentra en tensión es la propia posibilidad de supervivencia. A su vez, el territorio para la vida se relaciona con la necesidad de "volver" o crear una nueva cotidianeidad no conflictiva que permita el despliegue del modo de vida deseado. 


\section{Estrategias para la producción del territorio: la articulación con la Universidad}

El dispositivo del consenso social produce un sistema de alianzas basadas en vínculos mercantiles que construyen un "cerco", un límite a la visibilidad y posibilidades de crecimiento de la organización en lucha. En el discurso emerge una "verdad" que es escondida por este dispositivo: la contaminación y las enfermedades producidas. Así, la organización en lucha debe producir estrategias que le permitan superar o romper el cerco y hacer visible la "verdad". La estrategiapersigue el objetivo de hacer posible un avance en un juego de posiciones, en un enfrentamiento percibido. En el análisis de los discursos emerge la articulación con la Universidad como una estrategia.

Mientras que el dispositivo de consenso social se centra principalmente en la creación de relaciones mercantiles con diversas instituciones barriales para impedir que el conflicto exceda esta dimensión espacial, la organización en lucha ha centrado su estrategia en la posibilidad de tejer vínculos con instituciones relacionadas al ámbito de la ciencia. Las articulaciones emergen como la posibilidad de generar avances o acumulaciones en la consecución del objetivo deseado.

Para estos colectivos en lucha, el apoyo en opiniones de especialistas y la producción de datos propios resulta clave como estrategia para "hacer salir a la luz" aquello que se encuentra "a la vista" pero oculto por el poder:

La justicia vinieron a hacer las pericias, vinieron a hacer pericias del aire para tomar muestras $y$, bueno, el perito de parte de la justicia, porque había peritos de parte de Porta, de parte nuestro y de parte de la justicia, del fiscal, y bueno, supieron hacer una buena tramollita ${ }^{8}$ que se dio cuenta el, nuestro perito, y salieron a favor de ellos, salieron favor de ellos por eso la causa se archivó. $Y$ ahora está en otra instancia, porque está en otra parte, no me acuerdo cómo se llama. EO2: Esta Observada. EO1: Ah, en un juez de control para observación, pero en realidad las primeras pericias se dieron favorables por que supieron hacer bien ahí una trampita con los micro gramos y esas cositas. EO2: 0 sea adulteraron el resultado, el resultado dio sumamente alto a lo que está permitido para ... lo que (-) ¿Cómo es que se dice? por el (-) ¿cómo es el de la salud? ... ER1: ¿La Organización Mundial de la Salud? EO1: Claro, tenés un valor como todo, acá dio altísimo. EO2: tenés un tope y dio alto, pero ellos supieron cambiarle de microgramo a otra medida, entonces así fue favorable, cuando el fiscal lo ve, y si, el químico no es, entonces se apoyaba en el químico que él había puesto. El químico que él había puesto le dijo que estaba todo bien, entonces ¿Qué hizo? archivó la causa por que le faltaron elementos (VUDAS- 53:14). 
Aquí emerge el verbo "saber" conjugado en tercera persona del plural que indica un conocimiento ajeno. Este "saben" remite a un conocimiento de las "trampitas" que "ellos" saben y que quienes luchan descubren de a poco por ser "amateur". Así, se hace presente una idea del conocimiento científico atravesado por relaciones de poder que lo manipulan y alejan de los procedimientos que lo convierten en conocimiento válido. La referencia a la OMS expresa un recurso de poder por parte del enunciador, al tiempo que da cuenta del parámetro desde el cual se evalúan los resultados.

De allí que la discusión en torno al "para qué" del conocimiento, la pregunta y reflexión crítica sobre el rol y deber de aquellos que "concentran" un recurso al cual pocos acceden, asuma sentido:

\begin{abstract}
Por ALGO uno estudia en la Universidad ¿Para qué estudias? Saber, el saber no es solamente para vivir del saber, cuando vos sabes te debes al otro porque sabes más, entonces si vos estás viendo que el otro está siendo damnificado y no lo sabe vos que si lo sabes tenés una obligación ética y moral. $Y$ eso también se enseña en la Universidad. Y se ve que a veces la ética es una materia que no es obligatoria, son de esas alternativas que si querés la haces y sino no la haces, debe ser algo así. Cuando vos me preguntabas cómo se involucra la Universidad en esto, ahora están en la semana del derecho ambiental en la Universidad Nacional de Córdoba, que nos han ofrecido un stand dentro del Pabellón Argentina, vamos a compartir con otra gran cantidad de problemas ambientales, vamos a tener la posibilidad de tener nuestro stand, nuestra información. Es decir, la mesa permanente de Derechos Humanos, que también está el Observatorio de derechos Humanos, también nos abrió las puertas. Es decir, dentro de la Universidad tenés aquellos, un Conrero que se raja las vestiduras por una cosa y tenés otra gente muy buena que te da una mano y también es de la universidad Nacional (VUDAS54: 19).
\end{abstract}

En el extracto, la entrevistada construye una vinculación entre "por" algo y "para" algo. Así, los sujetos se ven motivados a estudiar por un compromiso con el otro. Este compromiso debe estar vinculado al deber moral del sujeto que sabe y limita su voluntad de lucro en virtud de mostrarle a los demás el riesgo en el cual se encuentran. La experiencia de los sujetos sobre sus cuerpos se relativiza ya que los químicos se constituyen como "armas silenciosas" que matan lentamente, incluso antes que el cuerpo pueda advertir que se encuentra en peligro. Se trata de un cuerpo que transita por la enfermedad ineludible aun cuando no tenga certezas. De allí, que sea necesario un discurso externo que pueda dar cuenta del peligro, de los daños a través de pruebas, antecedentes y figuras reconocidas. De este modo, la estrategia de desarrollar vínculos con instituciones da cuenta de un proceso de lucha por el discurso científico, como modo de superar los límites construidos por el dispositivo de consenso social y producir un nuevo territorio, apto para la vida humana. 
Así, la Universidad emerge como un actor de central importancia al ser la voz legitimada en cuanto al conocimiento científico y es aquella que puede validar o impugnar los discursos sobre el saber que sostienen las organizaciones. Así, la Universidad aparece como un territorio de conflicto per se en donde en algunos casos actúa como dispositivo de poder, cuando se inserta dentro de la red de instituciones vinculadas a las relaciones mercantiles, mientras que en otros emerge como parte de la estrategia de los colectivos en lucha. En la cita que sigue se expresa esta ambigüedad:

ER: ¿Con la Universidad por ejemplo, han tenido alguna relación? ¿Aportaron algo o no? EO1: Si, estos últimos tiempos, o sea ... para la causa poca, si tenemos o hemos tenido mucho apoyo de gente, qué se yo, de la Escuela de... Medio Ambiente, de Psicología, de, o sea un apoyo para ver en qué se puede hacer, pero en cuanto para el tema de la justicia no fue nada favorable, o sea lo que intervino la Universidad fue cuando nos adulteraron los resultados y nos mataron EO2: Que Yiorio está en la facultad EO1: Ahí te das cuenta, todo va cerrando EO2: Ahí está el señor postulándose de nuevo EO1: Si, hoy está en campaña EO2: Claro, está en campaña EO1: Está hoy en la... en las elecciones ¿no tienen elecciones en la facultad? EO2: Ah, están de elecciones y el señor está ahí, altísimo postulándose, pero por debajo hacen estas cosas EO1: Por debajo de la alfombra (VUDAS53:17).

Este extracto expresa la diversidad que articula la Universidad, sin embargo, sugiere dos planos de acción: uno institucional, orgánico y otro más singular o marginal. El primero remite a una lectura del accionar de la institución en sentido general que se relaciona con la corrupción, con hacer las cosas "por debajo", aquello no visible, "debajo de la alfombra". Estos léxicos de uso alegórico señalan una desconfianza sobre el accionar de la Universidad como institución, una desconfianza fundada en una experiencia anterior que se vincula a una persona en particular pero que ocupa puestos de poder dentro de la institución.

Por otra parte, las articulaciones con el colectivo en lucha se reducen a decisiones individuales de "gente" puntual. Esta forma de enunciación sugiere que dichas articulaciones son singulares aun cuando traccionan a la institución y expresan diversidades y tensiones. Estas decisiones individuales se enmarcan, desde este discurso, en la autonomía y libertad de cátedra. A su vez, se explica la articulación ya que la Universidad se encuentra en "zona sur" y estos sujetos habrían tomado consciencia de que la institución no es una "isla" y que ella, también se encuentra amenazada por la posibilidad de explosión de la fábrica Porta.

Así, en cuanto a la articulación con la Universidad encontramos dos aspectos en relación al territorio. Primero, el reconocimiento de la Universidad como territorio de lucha por sí 
mismo, que expresa las tensiones que articulan la sociedad y segundo, la visión estratégica de relacionamiento con aquellas porciones de la Universidad que los colectivos puedan establecer como forma de protección y defensa del territorio amenazado.

De esta manera, la Universidad es un territorio en conflicto por sí mismo donde su adhesión o rechazo implica un recurso de poder en la lucha. Permite respaldar el discurso de las organizaciones y luchar por la defensa del territorio.

El conocimiento científico permite "ver" aquello que en la vida cotidiana algunos experimentan pero otros no. El acceso al conocimiento científico por parte de algunos implica la obligación de información y compromiso. A su vez, este compromiso debe ser enseñado por la universidad que debe encargarse de formar profesionales vinculados a las necesidades del pueblo. Se trata entonces de un conocimiento que, desde esta perspectiva, debe encontrar su fundamento en la vinculación con lo social y no ser un conocimiento ajeno.

En la disputa por el conocimiento no se pone en discusión la veracidad del conocimiento científico en general sino más bien, las manipulaciones que el poder hace sobre este. De allí que obtener estudios "propios" implica una estrategia que permite "develar" la verdad. Solo así se garantiza el correcto procedimiento y la rigurosidad. Así, el discurso científico aparece vinculado a los siguientes lexemas: "corrupción", "fraude", "chantada", "delincuente", "no se cumplió" y "tranfugueadas".

En otras palabras, el contar con datos propios resulta estratégico en el marco de la lucha por el territorio. Mientras el conocimiento manipulado por el poder produce territorios de sacrificio, para el negocio, mercantilizados y atravesados por la especulación, las y los vecinos organizados defienden una producción de un territorio para la vida. Así, las condiciones de posibilidad de la vida, como las del medio ambiente, se vuelven objeto de disputa y, con ellas, la de los territorios a ser producidos. 


\section{Resultados: territorio de sacrificio}

Como ha emergido del análisis de las entrevistas es posible encontrar dos producciones de territorios que se encuentran en conflicto. Por una parte, aquel que produce la empresa Porta y por otra aquel que busca ser producido por las y los vecinos. El primero se caracteriza por el despliegue del dispositivo de producción de consenso social. Así, en este territorio se producen relaciones sociales instrumentales que construyen una red de relaciones y de articulación con diversos sujetos sociales que hacen posible la (re)producción de esta territorialidad. De esta manera, el dispositivo de producción de consenso habilita el control del territorio y de las relaciones que allí se configuran. De allí el sentimiento de "omnipotencia" de la empresa que emerge en el discurso de las entrevistadas. En otras palabras, la mercantilización es la principal característica de este territorio y abarca los cuerpos, las relaciones sociales y el espacio.

La mercantilización de la vida se hace evidente allí donde es sometida al cálculo costobeneficio en términos económicos. Se configura entonces una vida cotidiana atravesada en torno al conflicto, donde todos los lazos sociales se encuentran articulados en torno a esta tensión.

En oposición a este territorio, las y los vecinos organizados en VUDAS luchan por la producción de un territorio para la vida que se caracteriza por la afirmación y valoración de los cuerpos que allí habitan así como también, la lucha por la preservación de la vida. El lenguaje de guerra es recurrente en este conflicto ya que lo que se encuentra en tensión es la propia posibilidad de supervivencia. A su vez, el territorio para la vida se relaciona con la necesidad de "volver" o crear una nueva cotidianeidad no conflictiva que permita el despliegue del modo de vida deseado.

La intersección entre el dispositivo de producción del consenso social y la estrategia de articulación con la Universidad configura un territorio, en la particular relación de fuerza que se establece entre el dispositivo y la estrategia. Así, en el caso analizado, el poder del dispositivo para producir el territorio es superior al de la estrategia, por más que esta presenta potencia para la producción del territorio y lo tensiona de modo constante. Sin embargo, en este momento del conflicto, la potencia de la estrategia aún no logra romper el "cerco" que construye el dispositivo de consenso social. De este modo, y siguiendo a 
Svampa (2008) y Zibechi (2017) lo hemos denominado como "territorio sacrificables" o "áreas de sacrificio".

Los territorios de sacrificio son aquellos en los cuales el capital produce un uso del suelo que se hace incompatible con la vida. Son territorios que se encuentran dispuestos para las necesidades de las diversas fracciones de capital. Así, estos territorios se estructuran y asumen su forma a los fines de garantizar la acumulación. Sus características generales son la primacía del valor de cambio, frente al valor de uso. Estos territorios resultan claves para posibilitar el avance de las formas productivas especulativas, extractivas y tóxicas. Los territorios de sacrificio dan cuenta de un proceso de reordenamiento espacial asociado a la "zonificación" que modifica los patrones de uso de suelo, eximiendo algunos de la actividad extractiva, mientras que otros quedan dispuestos a tal fin.

A diferencia de lo que plantean autoras como Svampa, no se trata de espacios alejados, "libres" o "vacíos", con baja densidad poblacional, sobre los cuales el capital produce un discurso que gira en torno a la revalorización y la productividad ${ }^{9}$ (Svampa, 2015) sino, que se trata de espacios donde el uso principal del suelo es el residencial, con grandes concentraciones demográficas, dentro del ejido urbano que conviven forzosamente con actividades productivas que producen muertes por contaminación. En este espacio se registra un conflicto en torno a la regulación de los usos legales del suelo que se expresa en sus progresivas modificaciones a través del tiempo.

El principal dispositivo que opera y produce este territorio es el consenso social que le permite al capital disponer del territorio y reconfigurarlo de acuerdo a sus necesidades, controlando las oposiciones y luchas. Así, se asienta sobre la producción de relaciones sociales clientelares que construye una red de complicidades. Estas relaciones clientelares le permiten al capital moldear el territorio a la medida de sus necesidades.

De esta manera, los territorios de sacrificio se caracterizan por la modificación total y

9 Svampa propone el concepto de territorio de sacrificio cuando estudia el caso de la minería en Argentina. Sostiene la autora que estos se producen en aquellas regiones marcadas históricamente por la pobreza y la vulnerabilidad social, con una densidad poblacional baja, que cuentan con grandes extensiones de territorios "improductivos" y/o "vacíos". Así, se facilita la instalación de un discurso productivista y excluyente, al tiempo que constituye el punto de partida de la conformación de otros "lenguajes de valoración" en torno al territorio" (2008: 9) "La llamada propuesta de "zonificación", esto es, la definición de patrones de uso de suelo, apuntaría a definir qué espacios serían eximidos de la actividad extractiva, mientras que otros estarían disponibles para su recepción, todo lo cual remite claramente a la idea de "territorio sacrificables" o "áreas de sacrificio". 
abrupta del espacio (tala de árboles, migración de animales, aparición de sonidos y olores insoportables, constante circulación de camiones) y por la amenaza directa a la vidaenfermedades como cáncer, púrpura, abortos espontáneos y malformación en recién nacidos, que los conducen a la muerte.

En palabras de las y los entrevistados, se trata de territorios en guerra en donde la muerte por enfermedad no es una posibilidad sino una seguridad. La guerra es nominada como la "nueva guerra" o "guerra silenciosa" en referencia al efecto de los químicos en el cuerpo que matan a largo plazo y los efectos sobre cada organismo son difíciles de comprobar/relacionar.

La vida no es valorada como un fin en sí mismo, sino que se encuentra supeditada a la producción y acumulación. Así, la vida cotidiana y las relaciones sociales se encuentran atravesadas por el conflicto y el enfrentamiento al punto tal que este se introduce al interior de las relaciones de confianza de los sujetos en lucha y las fractura. La vivencia conflictiva de la vida cotidiana y la sensación de una experiencia diaria "insoportable" da lugar a una profunda apropiación del territorio, de aquel territorio que se pretende defender, ante quien lo ataca y transforma en su totalidad.

La apropiación se expresa en la estrategia de articulación con instituciones, en donde resalta principalmente la articulación con la universidad, en un marco de lucha por el conocimiento científico. La red de relaciones que construye esta estrategia persigue el objetivo de sortear la oscuridad del poder y permitir la emergencia de la "verdad" sobre la contaminación. Sin embargo, la efectividad de estas estrategias se ve limitada por el despliegue de los dispositivos de poder.

\section{Bibliografía}

ABADIA, Oscar. Moro. ¿Qué es un dispositivo?. Empiria. Revista de metodología de ciencias sociales. 2013, no 6, pp. 29-46. ISSN 1139-5737

AGAMBEN, Giorgio. ¿Qué es un dispositivo?. Sociológica. 2011, vol. 26, no 73, pp. 249-264. ISSN 2007-8358.

CIUFFOLINI, María Alejandra. Control del espacio y los recursos sociales: lógicas, relaciones y resistencias en la constitución de lo urbano. In NÚÑEZ, Ana y CIUFFOLINI, María Alejandra. Política y territorialidad en tres ciudades argentinas. Buenos Aires: El colectivo. 2011. 
CIUFFOLINI, María Alejandra. Espacio y política: pensar, decir y hacer investigación en territorios populares. Studia Politicæ. 2015, no 29, pp. 11-24.ISSN 1669-7405.

COMPOSTO, Claudia. Minería a gran escala y control social. Apuntes de investigación sobre el caso argentino. A contracorriente. 2012, no 3, pp. 254-290. ISSN 1548-7083.

DE CERTEAU, Michel. La invención de lo cotidiano. México: Universidad Iberoamericana, 1996. ISBN 9789688592595.

FOUCAULT, Michel. El sujeto y el poder. Revista mexicana de sociología, 1988, vol. 50, no 3, pp. 3-20. ISSN 0188-2503.

FOUCAULT, Michel. Dichos y escritos. Tomo III. Madrid: Nacional, 1994.

GIMÉNEZ MONTIEL, Gilberto. Territorio y cultura. Estudios sobre las culturas contemporáneas, 1996, no. 4, pp. 9-30. ISSN 1405-2210.

GODFRID, Julieta. Las estrategias de construcción de consenso social por parte de La Alumbrera en Amaicha del Valle. In VIII Jornadas de Sociología. Reconfiguración de las desigualdades en la Argentina actual: procesos, escalas y dimensiones, Buenos Aires, 2015, pp. 192.

GUATTARI, Félix y ROLNIK Suely. Micropolítica: cartografías del deseo. Madrid: Traficantes de Sueños, 2006.. ISBN 978-84-96453-05-0.

MURILLO, Susana. El conflicto social en Michel Foucault. Conflicto Social, 2008, vol. 1, no 01, pp. 156-180. ISSN 1852-2262.

NÚÑEZ, Ana; CIUFFOLINI, María Alejandra. Política y territorialidad en tres ciudades argentinas. Buenos Aires, El colectivo, 2011. ISBN 9789871497331.

O'CONNOR, James. ¿Es posible el capitalismo sostenible?. Papeles de población, 2000, vol. 6, no 24, pp. 9-35. ISSN 2448-7147.

SVAMPA, Maristella. Consenso de los Commodities y lenguajes de valoración en América Latina. Nueva Sociedad: democracia y política en América Latina. 2013. ISSN 0251-3552.

SVAMPA, Maristella; VIALE, Enrique. Maldesarrollo: La Argentina del extractivismo y el despojo. Buenos Aires: Katz editores, 2015. ISBN 109871566921.

SVAMPA, Maristella. Cambio de época, movimientos sociales y poder político. Buenos Aires: CLACSO. 2008.

ZIBECHI, Raúl. Movimientos sociales: nuevos escenarios y desafíos inéditos. OSAL, Observatorio Social Latinoamericano, 2006, no 21, pp. 221-230. ISSN:1515-3282.

ZIBECHI, Raúl. Zonas de dignidad. Extractivismo y resistencias. Barracas. Cooperativa editorial Tierra del Sur. 2017.

\section{Otras fuentes:}

El bioetanol presiona por más cupo: cómo está la industria en el mapa mundial (23 de junio de 2017). Agrovoz. http://agrovoz.lavoz.com.ar/actualidad/el-bioetanol-presiona-por-mas-cupo-como-esta-la-industria-en-elmapa-mundial. Recuperado el 10-07-2018.

Maíz: Córdoba sigue al frente de la producción de bioetanol (01 de junio de 2017). Agrovoz. http://agrovoz.lavoz.com.ar/agricultura/maiz-cordoba-sigue-al-frente-de-la-produccion-de-bioetanol.

Recuperado el 10-07-2018.

Combustibles: Córdoba aumentó en 38.500 toneladas el uso de maíz para etanol. (28 de Septiembre 2017). Agrovoz. http://agrovoz.lavoz.com.ar/actualidad/combustibles-cordoba-aumento-en-38500-toneladas-el-usode-maiz-para-etanol. Recuperado el 10-07-2018.

Porta: en 2017 nacieron dos bebés con malformaciones y uno murió (26 de junio de 2017). La Nueva Mañana. https://Imdiario.com.ar/noticia/16230/porta-en-lo-que-va-del-ano-nacieron-dos-bebes-con-malformacionesy-uno-murio 
Red Universitaria de Ambiente y Salud/ Médicos de Pueblos Fumigados. Análisis de la Salud Colectiva Ambiental de Barrio Parque San Antonio. Impacto en la Salud Colectiva por contaminación de una planta de Bioetanol. Informe preliminar Córdoba, 10 de Agosto 2013. Disponible en http://www.reduas.com.ar/wpcontent/uploads/downloads/2013/08/Analisis-Salud-Colectiva-Ambiental-Barrio-San-Antonio-FINAL1.pdf 